\title{
The Conundrums of the Estimated Magnitude of Food Waste Generated in South Africa
}

\author{
Machate Machate \\ Department of Environmental Science, University of South Africa, Tshwane 0001, Republic of South Africa
}

Corresponding Author Email: info@machate.co.za

https://doi.org/10.18280/ijsdp.150613

Received: 29 January 2020

Accepted: 13 July 2020

\begin{abstract}
Keywords:
food waste, inedible food portions, food waste estimation, food supply chain, criterion for calculating food waste, conundrums of food waste estimations, standardization of food waste definition, food
\end{abstract}

\begin{abstract}
This paper presents three conundrums that influence the estimation of the magnitude of food waste generated in South Africa. The first conundrum is the lack of standard definition of food waste which includes the inconsistencies and interchangeable use of food waste and food loss. The second conundrum relates to inconsistencies associated with the inclusion and exclusion criterion of inedible portions into food waste, and lack of clarity about the stages in the food supply chain at which food losses are considered food waste. The last conundrum relates to the credibility of sub-Saharan Africa's assumptions and methodological replicability used in the estimation of South Africa's magnitude of food waste generated. This paper highlights the influence of the three conundrums and relationship between qualitative and quantitative measurement of food waste variable by recalculating the food waste generation using the 20072009 data. Ultimately, the study results confirm that scientific quantification of variables should be based on clearly defined and validly demarcated qualitative variables to prevent methodological replicability and validity errors, as evident from the three conundrums identified in the South African food waste estimates.
\end{abstract}

\section{INTRODUCTION}

Understanding the magnitude of food waste and food losses generated at different stages in the food value chain is a significant step towards the monitoring and reduction of food wastage. However, such quantification of food waste should be arrived at through reliable, authentic and replicable scientific methods. The fundamental elements of valid and credible food waste data are twofold: Firstly, it is made of a consistent qualitative demarcation of the characteristics of the variable food waste, i.e. what is characterised as food waste and what is not. Secondly, consistent quantification of the value of the clearly defined food waste variable [1]. Consistent application of these methods leads to reliable and replicable methods of quantifying the magnitude of food waste generated.

This study identified the use of non-standard definitions of food waste as the first conundrum that inhibits reliable and scientific quantification of food waste generated in South Africa. Although myriad authoritative authors in food waste studies have proposed several definitions, there is no internationally agreed upon standard definition of food waste yet. Three major questions emerge from this conundrum as a result, namely:

1. Should inedible materials (i.e. peels, bones and etc.) be included or excluded in the food waste definition?

2. Are the concerps food waste and food loss synonymous? and

3. At what stages of the food supply chain are the loses or wastages characterised as food waste or food loses?

The challenge of the food waste definition (conundrum 1) is more critical, especially when secondary food waste related data is used to quantify food waste, as it is the case in Oelofse and Nahman [2]. The challenge of lack of standards food waste definition is significant, primarily because what one person includes or excludes from what he or she regards as elements of food waste vary considerably from the next person. Consequently, at any society with different individual understandings of constitutes food waste and what not, the final items contained in a food waste bin which subsequently informed the national estimates of the magnitude of food waste remains subjective than objective. Consequently, the data of food waste itself remains a mobile variable (non-credible) due to the variability in what various, food waste generators, scientists and institutions include or exclude as food waste, by virtue of food waste definition acceptable to that particular group or individuals. Thus, this study presents a methodological argument about the current approaches used to characterise and quantify the magnitude of food waste, using South Africa as a case study.

Oelofse and Nahman [2] estimated the magnitude of South Africa's food waste generated between 2007 and 2009 at 9.04 million t per annum or $177 \mathrm{~kg} /$ capita/ annum. Firstly, it is observed that Oelofse and Nahman [2] have excluded food imports and exports in their estimation. No rationale was provided for the exclusion of food imports and exports in the estimation of South Africa's magnitude of food waste generated in the period under review. Secondly, the South African food waste estimation was calculated based on average food generated in the period 2007 to 2009, using secondary data from the Food and Agricultural Organization [3]. The use of secondary data in the later estimations magnified the reliability challenges associated with the three methodological conundrums highlighted earlier. The inconsistent charecterization of the food waste variable by individual researchers who collected the field data remain the centre of the problem that questions homogeneity and 
authenticity of the values of the data, which has been used in the estimates in Food and Agricultural Organization [3].

The Food and Agricultural Organization [3] used the ratio of food wasted and food lost to estimate food waste. In calculating the amount of waste, Food and Agricultural Organization [3] followed the assumed food waste or loss rate per commodity group for sub-Saharan Africa suggested (Table $1)$.

Table 1. Estimated sub-Saharan Africa's food waste and losses rate per commodity group in five food supply chain stages

\begin{tabular}{c|ccccc}
\hline $\begin{array}{c}\text { Commodity group } \\
\text { [1000 tonnes] }\end{array}$ & $\begin{array}{c}\text { Agricultural } \\
\text { production }\end{array}$ & $\begin{array}{c}\text { Post-harvest } \\
\text { handling and storage }\end{array}$ & $\begin{array}{c}\text { Processing and } \\
\text { packaging }\end{array}$ & Distribution & Consumption \\
\hline Cereals & 6 & 8 & 3.5 & 2 & 1 \\
Roots and tubers & 14 & 18 & 15 & 5 & 2 \\
Oil seeds and pulses & 12 & 8 & 8 & 2 & 1 \\
Fruits and vegetables & 10 & 9 & 25 & 17 & 5 \\
Meat & 15 & 0.7 & 5 & 7 & 2 \\
Fish and seafood & 5.7 & 6 & 90.1 & 15 & 2 \\
Milk & 6 & 11 & 0.1 & 10 & 0.1 \\
\hline
\end{tabular}

Table 1, constitutes the third conundrum that is the focal point of the current review, primarily because Oelofse and Nahman [2] relied on this methodological aspect in calculating the estimated magnitude of food waste generated in South Africa. In adopting the principles in Table 1, the total weighed food waste in five food supply chain stages across seven commodity groups were added together into the final estimated magnitude. The first challenge observed with this approach was the failure by Oelofse and Nahman [2] to differentiate between food waste and food loss data during the estimations of South Afrfica's magnitude of food waste generated. Consequently, both data sets of food waste and food losses formed part of the input data into the estimations. Thus, creating an impression that the concepts food waste and food losses are synonymous and homogenous. If the opposite was true, their data sets could not have been added together during the calculation. The third conundrum comes with the reliance of the estimations on sub-Saharan Africa's assumptions whose credibility, reliability for South Africa is questionable. The importance of this conundrum is magnified by caution raised by $[5,6]$ who independently and unanimously acknowledged that there was a significant data gap during the development of the sub-Saharan African food waste generation rate. However, despite the identified data gap, Oelofse and Nahmann [2] raised on such data in estimating the national food waste generation rate. Clearly, relying on the data with significant gap represents a perpetual methodological flaw in research. On its own, this challenge sufficiently discredits the estimated results of South Africa's food waste. Other than relying on a particular formula with input data variables that was not credible, an alternative for Oelofse and Nahmann [2] would have been to find an alternative mathematical formula whose input data could pass credibility test. The data gap identified should have been cured before the sub-Saharan African assumptions were used.

Secondly, the socio-economic variability of the countries in Table 1, whose data were used to estimate sub-Saharan Africa's food waste generation rate is so significant to be ignored. This factor cannot be downplayed, given the significance and influence of the socio-economic profiles of societies in waste generation rates.

The third conundrum is the methodological replicability of the current approach used to estimate South Africa's food waste. This conundrum relates to the validation of the calculated estimates of South Africa's food waste quantities using the exact data but different credible and valid formulae. Key focal question here is whether two or more credible and valid methods inputting same data will yield same estimations for food waste generated in South Africa during the 2007 and 2009. Through factoring the elements of each identified conundrum in re-calculating the food waste generation rate using the same 2007 and 2009 data used by Oelofse and Nahman [2], this question is answered. If the recalculated results, having factored the elements of each conundrum yield exactly the same estimations by Oelofse and Nahmann [2], then the methods are confirmed as replicable, but if the recalculated results different, the opposite is proven. Ultimately, this conundrum was preceded by the first two which were discussed earlier. This paper uses three scenarios to demonstrate how the three methodological conundrums influence the estimated magnitude of food waste generated in South Africa.

\section{METHODS AND TECHNIQUES}

This paper used secondary data on estimated food waste generated in South Africa between 2007 and 2009 from Oelofse and Nahman [2]. In-depth exploratory and explanatory analysis of peer reviewed and published journal articles and reports on the different aspects of food waste were conducted following Creswell et al. [7] and Leedy and Ormrod [8]. In-depth reviews of authoritative literature sources involved qualitative analysis of the food waste definition, which lead to a detailed breakdown of different characteristics of what is and/or not food waste. From the different elements and components of food waste, this paper adopted exploratory search approach to examine supporting and contradictions in myriad of existing definitions of the food waste. Explanatory research approach was evoked explain various concepts related to food waste, identify similarities and differences as well as their implications in food waste estimation. The two (exploratory \& explanatory) analysis methods qualitatively informed the logical formulation of the entire research study. Semi-quantitative analysis of South Africa's food waste generation rate was done using the secondary data referred to earlier and ultimately lead to the synthesis of the study results. The recalculation of the magnitude of food waste generated in South Africa during 2007 and 2009 were a demonstrative example of the impact of qualitative characteristics of a variable on the final quantitative determination of the estimated total food waste generated per annum in different scenarios, hereafter referred as the three conundrum in this paper. 


\section{DISCUSSION OF THE RESULTS}

The magnitude of South Africa's food waste generated between 2007 and 2009 was estimated at 9.04 million tonnes, based on the methodology discussed in the introductory section of this paper [2]. The details of the estimates are presented in Table 2.

Table 2, presents a status quo scenario which is the estimated magnitude of food waste generation by Oelofse and Nahmann [2]. In 2013, these estimates were updated to 10.2 million tonnes by De Lange and Nahman [9] by adding imports and subtracting exports at the distribution stage. De Lange and Nahman [9] addressed the first gap which existed from Oelofse and Nahmann [2]. Thus, improved the initial calculation and consequently addressed one of the conundrums which existed in the estimated magnitude of food waste. However, the three methodological conundrums under this paper remained unresolved. From Oelofse and Nahman [2] to De Lange and Nahman [9], it is evident how food waste estimates change with each qualitative ratification of the methodological conundrums. This further demonstrates the importance of methodological credibility in both basic and applied research, especially in improving the authenticity of national estimates of food waste generation, as is intended by the current study.

Table 2. Estimated food waste and losses for South Africa

\begin{tabular}{|c|c|c|c|c|c|c|}
\hline $\begin{array}{c}\text { Commodity group } \\
{[1000 \text { tonnes }]}\end{array}$ & $\begin{array}{c}\text { Average production } \\
{[1000 \text { tonnes }]}\end{array}$ & $\begin{array}{c}\text { Agricultural } \\
\text { production }\end{array}$ & $\begin{array}{c}\text { Post-harvest } \\
\text { handling and storage }\end{array}$ & $\begin{array}{c}\text { Processing and } \\
\text { packaging }\end{array}$ & Distribution & Consumption \\
\hline Cereals & 13154 & 789.3 & 989 & 398 & 220 & 108 \\
\hline Roots and tubers & 2017 & 282.4 & 312 & 213 & 60 & 23 \\
\hline Oil seeds and pulses & 453 & 54.4 & 32 & 29 & 7 & 3 \\
\hline Fruits and vegetables & 8230 & 823 & 667 & 1685 & 859 & 210 \\
\hline Meat & 1587 & 238.1 & 9 & 67 & 89 & 24 \\
\hline Fish and seafood & 224 & 12.8 & 13 & 18 & 27 & 3 \\
\hline Milk & 3119 & 187.1 & 323 & 3 & 261 & 2 \\
\hline Total & & 2387 & 2344.6 & 2413.4 & 1523 & 372.7 \\
\hline
\end{tabular}

Source: Adapted from [2]

\subsection{Lack of standard definition of food waste}

According to Keller [1] data refers to "the observed values of a variable" and accordingly, "a variable is some characteristics of a population or sample". Food waste is a qualitative variable, while Oelofse and Nahman [2], attempted to estimate the value (magnitude of food waste quantities generated) of the variable in South Africa. Furthermore, to estimate the value of the variable, a consistent definition or characterisation of what is food waste and what is not needs to be cleared. This challenge is inherent in the current estimates Oelofse and Nahman [2] and De Lange and Nahman [9], among others. Another challenge inherent from the two previous above is their lack of operational definition of what they regard as food waste and what is food loss in their consecutive studies.

The second issue emerging from the food waste definition challenge is the ongoing debate about the difference between food loss and food waste. Gustavsson [4], an authoritative author whose methods of estimating food waste was claimed to have been adopted by Oelofse and Nahman [2] draws a distinction between food losses and food waste. In contrast, Oelofse and Nahman [2] failed in their estimations to distinguish between the two concepts or variables (food waste and food loss). The evidence of deviation by Oelofse and Nahman [2] qualitatively disposes them to errors which are not inherent from Gustavsson [4]. Consequently, Oelofse and Nahma [2] and Gustavsson, Cederberg and Sonesson [4] became methodologically different in their qualitative definition of food waste. It is irreconcilable how anyone can justify the values of qualitatively different variables (food waste and food loss) remained the same, while the elements or charecteristics of the variables are different. Hence, it can also be seen that a researcher who accept that food loss and food waste are synonymous, the quantitative value of their variable (food waste) will automatically differ from the one sees food losses as different from food waste.

\subsubsection{Food waste and food loss}

According to Lipinski [10] food waste refers to good quality food that is discarded before or after it spoils. Lipinski [10] charcterises food waste as discarded food materials that are of good quality and were intended or reasonably expected to be consumed by human. In the above definition, Lipinski [10] provides a qualifier to differentiate between food that is of good quality for human consumption and that which is not. Food that was not reasonably intended for human consumption before or after it spoiled does not constitute food waste, as understood from Lipinski [10]. The Swedish Institute of Food and Biotechnology [6] argues that a decrease in food quality or quantity before food products reach their final stages of the supply chain reduce the amount of food suitable for human consumption as food losses. The Swedish Institute of Food and Biotechnology [6] defines food waste as the discarding of food products (edible food materials) that are fit for consumption or to proceed in the food supply chain. In the above [6], food waste, as opposed to food losses often happens in the late stages of the food supply chain, mostly in the distribution and consumption levels. The definitions of food losses and food waste by the Swedish Institute of Food and Biotechnology [6] are in consistent with the suggestion that food losses are one of the potential causes of food waste, in line with the definition of food waste by Lipinski [10]. Effectively, the Swedish Institute of Food and Biotechnology [6] denounces food waste and food loss as synonymous, and brings forth their causeeffect relationship.

According to Grezetti [11], food waste refers to a discarded, lost and/or degraded edible material that were intended for human consumption in any stage of food supply chain. Once more, [11] concurs with the former authors that food waste is made of only food materials that were intended for human consumption, which were ultimately discarded due to loss in quality and other causes. Thus, food loss is accordingly one of the causes of food waste. Lipinski [10], Grezetti [11] and The Swedish Institute of Food and Biotechnology [6] are 
consistent in their definition of food waste and its distinction from food loss.

In contrast, Fusions [5] defines food waste as any food and inedible parts of food that are removed from the food supply chain, either for recovery or disposal. Food waste excludes packaging, food produced for animals and valorisation and conversion materials (bio-materials). Fusions [5] introduces a number of contradictions in the definition of food waste, including the inclusion of recovery of food, inedible parts of food and biomaterials.

According to De Lange and Nahman [9] food waste refers to food losses that occur during the food supply chain (including pre-consumer food losses and post-consumer food waste). De Lange and Nahman [9] views food waste as synonymous to food losses. Although Oelofse and Nahman [2] did not specify the definition of food waste they adopted in the estimation of the food waste quantity of South Africa, they however make reference to a definition by the European Commission [12]. In the later [12], food waste is referred to as composed of raw or cooked food materials before, during and after meal preparations in households, including food losses in the manufacturing, distribution, retail and food services activities. The latter definition is the least comprehensive of all discussed in this paper. The above definition excludes food losses happening in food supply chain stages other than manufacturing, distribution, retail and food services activities. Similarly, the definition of food waste by European Commission (2010) excludes losses and wastage at the production stage (on farm)

On the other hand, Gustavsson, Cederberg and Sonesson [4] defines food loss as the decrease in food quality or quantity in the early stages of the food chain, reducing the amount of food suitable for human consumption. If the Gustavsson, Cederberg and Sonesson [4] definition of food loss is to go about, then the reference of food loss at the later stages of the food supply chain, i.e. distribution, retail and food services activities can be interpreted as synonymous to food waste as per the European Commission [12] and De Lange and Nahman [9]. An immediate challenge observed from Oelofse and Nahman [2], is lack of clarity about their adopted or adapted definition of food waste that was used in the estimation of the magnitude of South Africa's food waste generated during the 2007 and 2009 period. Consequently, the analyses in this paper, observed inconsistencies between how food waste has been qualitatively defined and the quantitative methods followed in the estimation of the amount of food waste generated in South Africa during the period under review.

Lipinski, Hanson [10] defines food loss as food that spills, spoils, incurs an abnormal reduction in quality such as bruising or wilting, or otherwise gets lost before it reaches the consumer. The definition of food loses by Lipinski, Hanson [6, 10] and Gustavsson, Cederberg [4] contradict that of the European Commission [12], Oelofse and Nahman [2] and De Lange and Nahman [9]. In an attempt to nationalise a food waste definition, this paper refers to the National Environmental Management: Waste Act of 2008 [13], which defines waste as "any substance, material or object [food], that is unwanted, [unfit for human consumption], rejected, [even for further processing], abandoned, discarded or disposed of , or that is intended or required to be discarded or disposed of, by the holder of that substance, material or object, , whether or not such substance, material or object [food] can be re-used, recycled or recovered...".

Gustavsson, Cederberg [4] defined food waste as the discarding of food products that are "fit for consumption". In Gustavsson, Cederberg [4], the fitness of food for consumption is not specific or limited to humans. However, given the definition of and exclusions from the food definition by Fusions [5], fitness of food for consumption will refer to human quality standards. Suitability of food for human consumption and discarding or removal from the food supply chain remains central in Gustavsson, Cederberg [4] and previous definitions of food waste. Therefore, in a long legislatively aligned narrative, food waste refers to any food [only edible materials] that is unwanted, rejected, abandoned or disposed of, or that is intended to be discarded or disposed of, by the holder, whether or not it can be re-used, recycled or recovered. Therefore, the inclusion and/or exclusion of all food losses in the definition of food waste increase and/or decrease the quantity of variables that constitute food waste, respectively.

\subsubsection{Inclusion and exclusion of inedible materials in the food} waste

Lipinski, Hanson [10] excludes inedible materials associated with food from the definition of food waste. Inedible materials are excluded from the food waste definition because they were not intended nor were, they reasonably expected to be consumed by human. The former [10] contrast Fusions [5], who characterises food as any substance or product, whether processed, partially processed or unprocessed, intended to be, or reasonably expected to be consumed by humans. Fusions [5] includes inedible materials in their definition of food waste, while they exclude inedible portions in their definition of food. The first point of contention in the Fusions [5] is that their estimate of food waste quantities includes inedible materials which were not intended to be, or reasonably expected to be consumed by human as per their own definition of food waste. Inclusion or exclusion of the inedible portion of food waste becomes important when considering options for food waste minimisation towards improved food security and is important from a waste management and greenhouse gas emissions point of view. In the first instance, one would like to focus on the edible portion of the waste whereas in the second instance, it is important to consider both edible and inedible portions. Therefore, the inclusion and/or exclusion of inedible materials in the definition of food waste increase and/or decrease the quantity of variables that constitute food waste, respectively. Hence, it is important that each researcher or individual clarifies what constitutes food waste in their waste bin or bag.

\subsubsection{The stages of food waste generation in the food supply} chain

According to Fusions [5], food supply chain is a connected series of activities used to produce, process, distribute and consume food. As a result, Fusion [5] categorises food supply chain into four stages, namely;

(1) primary production,

(2) manufacturing,

(3) retail and distribution, and

(4) food services and households [5].

According to Gustavsson, Cederberg [4] and The Swedish Institute of Food and Biotechnology [6], the food supply chain consists of five stages, namely;

(1) agricultural production,

(2) postharvest handling and storage,

(3) processing and packaging, 
(4) distribution, and

(5) consumption.

The immediate impact of the differences in the number of and grouping of food supply chain stages is the consistency of estimates of food waste magnitude when the approach of Oelofse and Nahman [2] are applied. Unfortunately, cumulative addition of the percentages across a commodity group would yield a far different estimate than individual calculation across each food supply chain stage. Consequently, the methods followed by Oelofse and Nahman [2] becomes invalid when a different number of categories of food supply chain stages are adopted as shown earlier where four instead of five stages are followed. Although this is not the primary focus of this study, a consistent global view of the food supply chain is important in the estimation of global food waste quantities, and thus its relevance to this study as well, as was in the South African National estimations by Oelofse and Nahman [2].

In addition, according to De Steer, Besana [14], food waste and food loses result from defect food products, unnecessary inventory, over production and inappropriate food processing within the food supply chain. A key question emerging from this is at what stages (if any) is food waste and/or food losses generated? According to Gustavsson, Cederberg [4] and The Swedish Institute of Food and Biotechnology [6], food waste generation starts at post-harvest stage. Given that Oelofse and Nahman [2] have adopted the approach of Gustavsson, Cederberg [4], and that there is no reason or disclosure of deviation by Oelofse and Nahman [2], it can be deduced that agricultural production stage was excluded in the estimation by Oelofse and Nahman [2]. Unfortunately, in the real estimations, Oelofse and Nahman [2] included the agricultural production stage, whose losses should fall within the definition of food losses than food waste. Conseqienetly, the recalculation of food waste estimatikons for 2007 is presented in Table 3. These recalculations exclude the agricultural production stage in line with the definition of food waste adopted by Oelofse and Nahman [2].
There is a difference of 1989.1 tonnes between the estimates of 9040.9 by Oelofse and Nahman [2] and 7051.8 of the recalculations, respectively. This difference is influenced by the adoption of the food waste definition starts from the postharvest stage of the food supply chain. Clearly, it is evident that having a clear cut and consistent stage from which food waste is generated has a significant influence in the estimation of this waste.

\subsection{The credibility of sub-Saharan Africa's assumptions}

The amount and rates of waste generation are influenced by many factors such as urbanisation [15], population growth [15, 16] social development [15], economic development [15, 16], change in consumption patterns [15], industrialisation [15, 17], and higher standards of living [16, 17], amongst others. Hence the difference in development levels of communities or countries represent a significant difference in the different waste generation profiles of such communities. This study took note of the significant gaps in the Human Development Index (HDI) of the 40 countries used to develop the subSaharan African food waste profile (assumptions). This HDI represents consumption levels and its influence in the food waste generation rate of each country [18]. Table 4 present three economic groups (income levels) of countries used by Gustavsson, Cederberg [4] and The Swedish Institute of Food and Biotechnology [6] to estimate the food waste generation rate per commodity groups across five food supply chain stages.

The representativeness of these countries in Table 4 by income levels were skewed towards low-income countries. Evidently, there were 24 low income countries as compared to, 9 low-middle income and 7 upper middle income categories [19]. The selection of many low income countries as data sources for the formulation of a constant factor (assumption) that would be used to estimate a regional waste generation rates while income in a key variable of waste generation significantly compromised the constant factor.

Table 3. Estimated food waste for South Africa from post-harvest to final consumption

\begin{tabular}{|c|c|c|c|c|c|c|c|}
\hline $\begin{array}{c}\text { Commodity group } \\
{[1000 \text { tonnes }]}\end{array}$ & $\begin{array}{c}\text { Average production } \\
{[1000 \text { tonnes }]}\end{array}$ & $\begin{array}{c}\text { Agricultural } \\
\text { production }\end{array}$ & $\begin{array}{c}\text { Post-harvest } \\
\text { handling and storage }\end{array}$ & $\begin{array}{c}\text { Processing and } \\
\text { packaging }\end{array}$ & $\begin{array}{c}\text { Distri } \\
\text { bution }\end{array}$ & $\begin{array}{c}\text { Consu } \\
\text { mption }\end{array}$ & Total \\
\hline Cereals & 13154 & 0 & 1052.3 & 423.6 & 233.6 & 114.4 & 1823.9 \\
\hline Roots and tubers & 2017 & 0 & 363 & 248.1 & 70.3 & 26.7 & 708.1 \\
\hline Oil seeds and pulses & 453 & 0 & 36.2 & 33.3 & 7.7 & 3.8 & 81 \\
\hline Fruits and vegetables & 8230 & 0 & 740.7 & 1872.3 & 954.9 & 233.1 & 3801 \\
\hline Meat & 1587 & 0 & 11.1 & 78.8 & 104.8 & 27.8 & 222.5 \\
\hline Fish and seafood & 224 & 0 & 13.4 & 18.9 & 2.9 & 3.8 & 39 \\
\hline Milk & 3119 & 0 & 343.1 & 2.8 & 27.7 & 2.7 & 376.3 \\
\hline Total & 28784 & $\mathbf{0}$ & 2559.8 & 26779.8 & 1401.9 & 412.3 & 7051.8 \\
\hline
\end{tabular}

Table 4. Income levels of the Sub-Saharan countries used to estimate South Africa's food waste percentage

\begin{tabular}{ccc}
\hline Low Income Countries & Lower-Middle Income Countries & Upper-Middle Income Countries \\
\hline Benin & Cote d'Ivoire & \\
Burkino Faso & Cameroon & Angola \\
Burundi & Kenya & Botswana \\
Central African Republic & Lesotho & Equatorial Guinea \\
Chad & Nigeria & Gabon \\
Democratic Republic of Congo & Sudan & Mauritania \\
Eritrea & eSwatini & Namibia \\
Ethiopia & Zambia & South Africa \\
Gambia & Ghana & \\
Guinea & & \\
Guinea-Bissau & & \\
\hline
\end{tabular}




\begin{tabular}{c}
\hline Liberia \\
Malawi \\
Mali \\
Mozambique \\
Niger \\
Rwanda \\
Senegal \\
Sierra Leone \\
Somalia \\
Tnited Republic of Tanzania \\
Togo \\
Uganda \\
Zimbabwe \\
Source: Compiled from [4, 6, 19]
\end{tabular}

Thus, the average food waste generation rate per commodity group across the supply chain stages should be treated with great caution. The Swedish Institute of Food and Biotechnology [6] cautioned that the Sub-Saharan African food waste quantities and percentages, including other regional estimations should be taken with "great caution", because there was a "major data gap for both waste percentages of losses and waste".

\subsection{Methodological replicability}

To quantify food waste generation, Fusions [5] recommends that such quantification should address aspects such as timeframe, materials type, destinations, boundaries of national food waste quantification study and that food waste quantities should be compiled based on a calendar year (from $1^{\text {st }}$ January to $31^{\text {st }}$ December). The former [5] also recommended that the period also accounts for seasonal variations in food waste generation rate. The estimations under review did not fulfil this requirement and there is not justification for such deviation [2]. A rolling programme on average of three years period for a specific sub-sector may be implemented where the quantification of food waste from all sectors becomes a challenge. Unfortunately, it is observed that the current South African estimates and the data used did not account for the exact dates of the data.

The quantification study should separate the amount of food waste for each destination, i.e. composting, crops ploughin/not harvested, anaerobic digestion, bio-energy production (biofuel, gasification \& pyrolysis), co-generation, incineration, disposal to sewer, landfill and food portions discarded to sea. It is also recommendable to quantify non-food waste materials such as animal feed, bio-based production materials/chemical processing. According to Fussions [5], food donations or surplus redistributed to charity are not considered food waste. Thus, it is important to also quantify food going for redistribution and the flows in between supply chain sectors [5]. Food waste should also be quantified according to food category (edible $\&$ inedible parts) and sector or food supply chain stage [5]. With the exception of edible and inedible category, Oelofse and Nahman [2], have estimated food waste and/or food loses in each of the five stages of the supply chain. In addition to the methodological recommendations by Fusions [5], the current study suggests that food waste quantities should also be correlated with other waste quantities of a country to test their closeness and comparability. This is more important in ensuring consistencies in the total estimated waste quantities of a country, and those of different waste categories, especially the total organic waste quantities of a country and the rate of food waste within organic waste.

In Fusions [5] emphasizes is made about the importance of specifying the particular year for which the data is compiled. The quantification is also expected to separately determine the total amount of edible, inedible parts and the combined quantities [5]. In general, numerous aspects of the estimation have compromised the replicability of the methods currently adopted in the estimation of the magnitude of South Africa's food waste generation rate.

\section{CONCLUSIONS}

The paper discussed three conundrums that are associated with the estimated magnitude of food waste, using South Africa as a case study.

Although these conundrums are not exclusive to South Africa, the selection of South Africa was for demonstrative purposes. Secondary, data was used to re-calculate food waste generated taking into account one of the three conundrums and compared with the final estimations that were arrived at by Oelofse and Nahman [2]. The difference demonstrated influence of each of the three qualitative conundrums on quantification of food waste generation.

The lack of standard food waste definition, credibility of sub-Saharan African food waste and/or food loss estimated rate per commodity group across five stages of the food supply chain, and methodological replicability, were the three conundrums identified. Principal elements of these conundrums were inconsistencies between the qualitative characterisation of what is and/or not food waste. Firstly, these inconsistences include among others, inability to distinguish between food waste and food losses during data collection. The second challenge involved the non-distinction on inclusion and/or exclusion of inedible materials from food waste. Thirdly, inability of the researchers to consistently estimate food waste based on the food supply chain stages from which the start of food waste is qualitatively expected to be generated and end. Ultimately, this study demonstrates that inconsistent qualitative characterisation of the variable "food waste" has a significant influence on the final quantification food waste generated in South Africa.

The significant contribution of this study is that credibility of a study is among others pillared in its methodological strength and credibility. Secondly, that qualitative characterisation of variables dictates the quantitative limitations and delimitations in data collection and analysis. In the reviewed South African estimates of food waste generation for 2007 and 2009, these methodological conundrums are identified, thus the final quantified results cannot be scientifically and methodologically accepted. The credibility of results from quantitative data should where applicable be verified and validated by using different credible 
quantification methods, if the two or more methods arrive at the same results, such gives more credibility. It is recommended therefore that further and empirical studies should be conducted in South African. Such future studies should clarify their operational definitions of food waste which would have been consistently adopted prior to data collection until the final determination of the country's food waste.

The limitation of this study was that no empirical data was collected. Having identified the methodological gaps in the current methods of estimating food waste generation will help improve the future methods used for estimating food waste.

\section{ACKNOWLEDGMENT}

This work is supported by the National Research Foundation (Grant No.: 121862).

\section{REFERENCES}

[1] Keller, G. (2014). Statistics for Management and Economics. 10 ed. Canada: Cengage Learning.

[2] Oelofse, S., Nahman, A. (2013). Estimating the magnitude of food waste generated in South Africa. Waste Management and Research, 31(1): 80-86. https://doi.org/10.1177/0734242X12457117

[3] Food and Agricultural Organisation. (2011). The state of food insecurity in the world: Addressing food insecurity in prostrated crises, F.a.A. Organisation, Editor. Rome. http://www.fao.org/3/i1683e/i1683e.pdf.

[4] Gustavsson, J., Cederberg, C., Sonesson, U. (2011). Global food Losses and Food Waste. Extent, Causes and Preventions. F.a.A.O.o.t.U. Nations, Editor. FAO. http://www.fao.org/3/a-i2697e.pdf.

[5] Fusions. (2016). Food waste quantification manual to monitor food waste amounts and progression: Reducing food waste through social innovation. Fusions. http://www.eu-

fusions.org/phocadownload/Publications/Food\%20wast e\%20quantification \%20manual\%20to\%20monitor\%20f ood $\% 20$ waste $\% 20$ amounts $\% 20$ and $\% 20$ progression.pdf.

[6] The Swedish Institute of Food and Biotechnology. (2013). The methodology of the FAO study: "Global Food Losses and Food Waste-extent, causes and prevention". http:/www.divaportal.org/smash/get/diva2:944159/FULLTEXT01.pdf.

[7] Creswell, J.W., Hanson, W.E., Clark Plno, V.L., Morales, A. (2009). Qualitative research designs: Selection and implementation. The Counseling Psychologist, 35(2): 236-264. https://doi.org/10.1177/0011000006287390

[8] Leedy, P., Ormrod, J.E. (2010). Practical Research: Planning and Design. New York: Pearson Education Limited.
[9] De Lange, W., Nahman, A. (2015). Cost of food waste in South Africa: Incorporating inedible food waste. Waste Management. 40:

167-172. https://doi.org/10.1016/j.wasman.2015.03.001

[10] Lipinski, B., Hanson, C., Waite, R., Searchinger, T., Lomax, J., Kitinoja, L. (2013). Reducing food loss and waste. https://www.wri.org/publication/reducing-foodloss-and-waste.

[11] Grezetti, B., Pretato, U., Lassaletta, L., Billen, G., Garnier, J. (2013). The contribution of Food waste to global and European nitrogen pollution. Environmental Science and Policy, 33: 186-195. https://doi.org/10.1016/j.envsci.2013.05.013

[12] European Commission. (2010). Preparatory study on food waste across EU 27. Bio Intelligent Service SAS. http://ec.europa.eu/environment/eussd/pdf/bio_foodwast e_report.pdf, accessed on Jan. 13, 2014.

[13] Republic of South Africa. (2008). National Environmental Management: Waste Act of 2008, D.o.E. Affairs, Editor. 2008: Pretoria. https://www.gov.za/sites/default/files/gcis_document/20 1409/32000278.pdf.

[14] De Steer, H., Wesana, J., Dora, M.K., Pearce, D., Gellynck, X. (2016). Applying Value Stream Mapping to reduce food losses and food wastes in supply chains: A systematic review. Waste Management, 58: 359-368. https://doi.org/10.1016/j.wasman.2016.08.025

[15] Tan, S.T., Ho, W.S., Hashim, H., Lee, C.T., Taib, M.R., Ho, C.S. (2015). Energy, economic and environmental (3E) analysis of waste-to-energy (WTE) strategies for municipal solid waste (MSW) management in Malaysia. Energy Conservation and Management, 102: 111-120. https://doi.org/10.1016/j.enconman.2015.02.010

[16] Scarlat, N., Motola, V., Dallemand, J.F., MonfortiFerrario, F., Mofor, L. (2015). Evaluation of energy potential of municipal solid waste from African urban areas. Renewable and Sustainable Energy Reviews, 50: 1269-1286. https://doi.org/10.1016/j.rser.2015.05.067

[17] Zumar, M., Bundhoo, S., Mohee, R. (2016). Potential of biogas production from biomass and waste materials in the small island developing state of mauritius. Renewable and Sustainable Energy Reviews, 56: 10871100. https://doi.org/10.1016/j.rser.2015.12.026

[18] Mohee, R., Mauthoor, S., Bundhoo, Z.M.A., Somaroo, G., Soobhany, N., Gunasee, S. (2015). Current status of solid waste management in small island developing states. Waste Management, 43: 539-549. https://doi.org/10.1016/j.wasman.2015.06.012

[19] The World Bank. (2016). World Bank Country and Lending Groups. How are the income group thresholds determined?

https://datahelpdesk.worldbank.org/knowledgebase/artic les/378833-how-are-the-income-group-thresholdsdetermined. 